\title{
Three-Year Trajectories of Caregiver Burden in Alzheimer's Disease
}

\author{
Josep L. Conde-Sala ${ }^{\mathrm{a}, *}$, Oriol Turró-Garriga ${ }^{\mathrm{b}}$, Laia Calvó-Perxas ${ }^{\mathrm{b}}$, Joan Vilalta-Franch $^{\mathrm{b}, \mathrm{c}, \mathrm{d}}$, \\ Secundino Lopez-Pousa ${ }^{\mathrm{b}, \mathrm{c}, \mathrm{d}, \mathrm{e}}$ and Josep Garre-Olmo ${ }^{\mathrm{b}, \mathrm{c}}$ \\ ${ }^{a}$ Department of Developmental Psychology, University of Barcelona, Barcelona, Spain \\ ${ }^{\mathrm{b}}$ Research Unit, Institut d'Assistència Sanitária, Salt, Spain \\ ${ }^{\mathrm{c} D e p a r t m e n t ~ o f ~ M e d i c a l ~ S c i e n c e s, ~ U n i v e r s i t y ~ o f ~ G i r o n a, ~ G i r o n a, ~ S p a i n ~}$ \\ ${ }^{\mathrm{d}}$ Memory and Dementia Assessment Unit, Institut d'Assistència Sanitaria, Salt, Spain \\ e Department of Neurology, Josep Trueta Hospital. Institut Catalá de Salut, Girona, Spain
}

Handling Associate Editor: Andrea Slachevsky

Accepted 14 April 2014

\begin{abstract}
Although numerous studies have examined caregiver burden in the context of Alzheimer's disease, discrepancies remain regarding the influence of certain factors. This study aimed to identify trajectories of caregiver burden in the context of Alzheimer's disease, as well as the factors associated with them. A cohort of patients and caregivers $(n=330)$ was followed up over three years. Growth mixture models were fitted to identify trajectories of caregiver burden according to scores on the Zarit Burden Interview (ZBI). A multilevel multinomial regression analysis was then conducted with the resulting groups and the patient and caregiver factors. In the sample as a whole, burden increased during follow-up $(F=4.4, p=0.004)$. Three groups were identified: G1 (initially high but decreasing burden), G2 (moderate but increasing burden), and G3 (low burden that increased slightly). Patients in G1 and G2 presented more neuropsychiatric symptoms and poorer functional status than did those in G3. Caregivers in G1 and G2 had poorer mental health. Spouses and, especially, adult children who lived with their parent (the patient) were more likely to belong to G2 (odds ratio [OR] 6.24; 95\% CI 2.89-13.47), as were sole caregivers (OR 3.51; 95\% CI 1.98-6.21). The patient factors associated with increased burden are neuropsychiatric symptoms and functional status, while among caregivers, being the sole carer, poor mental health, and living with the patient are of relevance.
\end{abstract}

Keywords: Burden, family caregivers, longitudinal studies, mental health, neurobehavioral manifestations

\section{INTRODUCTION}

Caregiver burden has been defined as a subjective measure of the physical, psychosocial, and financial pressure experienced by people who provide care to another individual. In the context of Alzheimer's disease (AD), the most widely used instrument for assessing this phenomenon is the Zarit Burden Interview (ZBI) [1].

Burden among the family caregivers of patients with $\mathrm{AD}$ and the factors associated with it has been widely

\footnotetext{
*Correspondence to: Josep L. Conde-Sala, Department of Developmental Psychology, University of Barcelona, Passeig Vall d'Hebron, 171- 08035 Barcelona, Spain. Tel.: +34 93 3125814; Fax: +34 93 4021368; E-mail: jllconde@ub.edu.
}

studied. The clinical features of patients that are most directly related to caregiver burden are the behavioral and psychological symptoms of dementia (BPSD) [2-6] and functional impairment [6-9], both of which are factors linked to the decision to place patients in residential care [10]. More severe anosognosia has also been related to greater burden $[11,12]$. Research has demonstrated that increased burden has a detrimental effect not only on the mental health of caregivers, where it is associated with higher levels of anxiety [13] and depression [7, 13-16], but also on their physical health [17]. It also has a negative effect on caregiver perceptions of the patient's quality of life $[18,19]$.

Certain socio-demographic factors, such as gender, are also of relevance, since women dedicate more time 
to caregiving duties and report greater burden, anxiety, and depression [20-24]. Another relevant factor is the care context: living with the patient is associated with greater burden $[25,26]$, and caregivers of patients who are later placed in an institution report less burden and fewer depressive symptoms following this placement [27].

There is, however, a need for a clearer understanding of how burden may change over time, since studies examining the associated factors have reported inconsistent findings. For instance, some research reports a decrease in overall burden over time [2], whereas other studies have found that it remains stable [8, 9] or even increases [3, 28]. With respect to symptoms of depression and anxiety in caregivers, one study documents a reduction in these symptoms due to progressive adaptation to the situation [29], whereas in another report the mean levels of depression and emotional exhaustion worsened over time, especially among wives and daughters-in-law [24]. In terms of the time spent providing care to the patient, one study identified three different trajectories, two of which involved an increase in time after 4.5-5 years, while the third was associated with a sharp decrease; however, the authors were unable to identify clearly the factors that determined these differences [30]. Finally, with regard to kinship, there is discrepancy over whether the greatest burden is experienced by spouses [22, 31-34] or by adult-child caregivers [26, 35-37].

The aim of the present study was to identify groups of caregivers with a similar trajectory of burden over a three-year period, and then to identify factors associated with each trajectory. This study was conducted based on the underlying hypothesis that there are groups of caregivers with similar evolutionary trajectories of burden. In order to achieve the study objectives, we used a person-centered statistical approach using growth mixture models (GMM) to characterize the trajectories of caregiver burden [38]. GMM models allow the identification of unobserved groups of individuals with similar trajectories. This approach is capable of detecting not only whether a group of persons changes on an outcome measure, but whether there are individual differences in the rates of change among group members.

\section{METHODS}

\section{Design and study population}

This was a prospective cohort study of noninstitutionalized patients with $\mathrm{AD}$ and their family caregivers over a period of three years.
All the patients were diagnosed with either AD according to DSM-IV (Diagnostic and Statistical Manual of Mental Disorders) criteria [39] or probable $\mathrm{AD}$ according to the criteria of the NINCDS-ADRDA (National Institute of Neurological and Communicative Disorders and Stroke/Alzheimer's Disease and Related Disorders Associations) [40]. The sample also comprised their respective family caregivers, defined as the person with main responsibility for helping the patient with activities of daily living (ADL). Patients were excluded if they presented vascular or traumatic events, alcohol or substance dependency or abuse, and if they had severe communication problems that prevented them from responding adequately to the assessment questions.

All the AD subjects were seen as out-patients in the Memory and Dementia Assessment Unit of the Santa Caterina Hospital in Girona (Spain) and formed part of the SIDEA research project (Seguimiento Integral de la Enfermedad de Alzheimer-Comprehensive Follow-

Up of Alzheimer's Disease). This project is an observational, longitudinal, and pragmatic cohort study. Using a standardized protocol it aims to describe and follow-up a large cohort of patients diagnosed with $\mathrm{AD}$, as well as their family caregivers, who receive outpatient medical and social care at secondary-level centers in our area. The present study forms part of this project and was approved by the Ethics Committee for Clinical Research of the local health authority.

The data corresponding to the baseline assessment of this study have been previously published [32].

\section{Socio-demographic data}

The socio-demographic characteristics of patients and caregivers (age, gender, marital status, level of education, family relationship, and whether they lived together) were recorded by means of a structured interview, the Cambridge Mental Disorders of the Elderly Examination (CAMDEX) [41].

\section{Clinical data regarding patients}

These data were collected by means of three instruments:

The Mini Mental State Examination (MMSE). This is a brief cognitive examination whose scores range from 0 to 30 [42]; the higher the score, the better the cognitive function.

Disability Assessment for Dementia (DAD). This scale, which was completed by caregivers, assesses a wide range of ADL: basic, instrumental, and leisure. It comprises 40 items and scores range from $0-80$ 
[43]. Higher scores are indicative of better functional status.

Neuropsychiatric Inventory (NPI). This instrument for evaluating behavioral and psychological symptoms in $\mathrm{AD}$ is administered to the caregiver. It comprises 12 subscales and scores range from 0-144 [44]. The higher the score, the more symptoms are presented by the patient.

\section{Clinical data regarding caregivers}

Two instruments were used to collect these data:

Zarit Burden Interview (ZBI). This questionnaire is designed to assess the burden experienced by caregivers and it comprises 22 items that are scored on a Likert scale ranging from 1 (never) to 5 (almost always). The total score therefore ranges between 22 and 110, and higher scores indicate greater burden [1].

SF-12 Health Survey (SF-12v1), the short form of the SF-36 Health Survey. Raw scores on this questionnaire yield a summary score on two broad dimensions: physical health and mental health. The possible score range on both dimensions is $0-100$ [45], and the higher the score, the better the respondent's health.

The number of daily hours spent caring for the patient were also recorded, and those individuals who were the sole caregiver were identified.

\section{Procedure}

In the initial interview, the aims of the study were explained to patients and caregivers, who were then interviewed separately. All the patients and their caregivers gave their written consent to participate in the study. The assessment instruments were administered by a clinical neuropsychology research team from the hospital.

The baseline assessment interviews were conducted between July 2003 and July 2012. Participants in the present study were followed up at 12,24 , and 36 months after baseline.

\section{Statistical analysis}

The descriptive analysis of categorical variables involved calculating frequencies and conducting comparisons by means of the Pearson $\chi^{2}$ test. For continuous variables, the linear mixed model was used to calculate the fixed effects ( $F$, ANOVA) and the simple effects of the estimated marginal means for each assessment point. A heterogeneous firstorder auto-regressive [AR (1)] covariance structure was used, as this provided the best fit to the unstruc- tured matrix and best fulfilled the parsimony criterion. The contrasts involving continuous variables were corrected by means of the Bonferroni test for multiple comparisons.

Growth mixture models (GMM) were fitted in order to characterize the trajectories of caregiver burden according to scores on the ZBI. The models were estimated using different numbers of latent classes, with multiple iterations being applied to each model using different random initial values so as to reduce the likelihood of a given model being erroneously identified as providing the best fit to the data. The optimum number of trajectories was determined by applying various indices of model fit and using the parsimony criterion to select the most appropriate model. The general procedure was as follows. First, a single-class model was fitted so as to provide a baseline against which the improvement in statistical fit could be measured. Models with an increasing number of classes were then progressively fitted, up to a maximum of five possible classes. The definitive number of classes was then determined on the basis of the following statistical fit parameters. The Akaike information criterion (AIC) [46], the Bayesian information criterion (BIC) [47], and the sample-adjusted BIC are descriptive indices of overall goodness of fit. These criteria are based on the distance between a candidate model and the "true" model, and they provide a likelihood-based measure of fit with penalty terms for the number of estimated parameters in the model (parsimony). When comparing models the general rule is that lower values of the AIC, BIC, and sample-adjusted BIC are indicative of better fit. The Lo-Mendell-Rubin (LMR) test [48] compares the fit of a given $k$ class model with that of the $k-1$ class model. A $p$ value less than.05 means that we can reject the null hypothesis that the $k-1$ class model provides a better fit than does the $k$ class model. Entropy is a measure that tells us about the extent to which the identified classes are different from one another, and it is based on the probability that a given individual has of belonging to each of the classes. If each subject in a sample has a high probability of belonging to a single class, then the model is said to have high entropy. Entropy ranges between 0 and 1, and values approaching 0.9 or higher indicate that the fitted model provides a clear classification of subjects.

After reaching a final solution for each model, each subject was assigned to a group on the basis of the fit with his/her observed trajectory. In order to identify the clinical and socio-demographic characteristics of patients and caregivers that were associated with the trajectory of burden, a multilevel multinomial 
regression analysis [49] was conducted, taking the groups resulting from the mixture model as the dependent variable, and the patient and caregiver factors as the independent variables.

For hypothesis contrasts the level of statistical significance was set at 0.05 . All data processing and analysis was performed using SPSS 17.0 for Windows (SPSS Inc.; Chicago), and Mplus7.11 (Muthén \& Muthén, Los Angeles).

\section{RESULTS}

\section{Sample description}

The initial cohort comprised 330 patients and their respective caregivers, of whom 235 completed the assessment at 12 months, 166 at 24 months, and 118 at 36 months. The remaining 212 cases were lost to follow-up during the three-year period, most commonly as a result of deterioration in the patient's status $(43 \%)$; the other causes were exitus $(15 \%)$, change of address (7\%), and other issues such as refusal to participate further or transport difficulties (35\%).

At baseline, the cases lost to follow-up $(n=212)$ were older $(z=2.4, p=0.015)$, scored lower on the $\operatorname{MMSE}(z=3.1, p=0.001)$, and had a worse functional status $(z=3.5, p<0.001)$ and more neuropsychiatric symptoms $(z=2.1, p=0.034)$, as compared with those who completed all four assessments $(n=118)$. The sample of caregivers presented no significant differences in terms of age, burden, or physical and mental health. The categorical variables gender, years of schooling, and family relationship showed no significant differences in either patients or caregivers.

\section{Clinical and socio-demographic data of participants}

The clinical data of patients revealed a progressive deterioration over the three years, especially in terms of cognition (MMSE, $F=20.2, p<0.001$ ) and functional status (DAD, $F=58.7, p<0.001$ ). With regard to behavioral and psychological symptoms, although the overall NPI score did not change significantly over time, some of the subscale scores decreased [NPI-Hallucinations $(F=2.8, p=0.039)$ and NPI-Depression $(F=3.7, p=0.011)]$, while others increased [NPI-Anxiety $(F=5.0, p=0.002)$ and NPIAberrant motor behavior $(F=3.0, p=0.031)]$.

Data for caregivers showed a progressive and significant increase over the three years in the number of daily hours spent caring for the patient $(F=270.9$, $p<0.001)$. Burden (ZBI) also increased over this period $(F=4.4, p=0.004)$, although the number of sole caregivers decreased $\left(\chi^{2}=10.5, p=0.014\right)$.

The progressive loss of cases to follow-up did not produce any significant changes in the proportions corresponding to the variables gender, years of schooling, family relationship, or living with the patient. As expected, the only variable that showed a significant difference in this regard was the age of patients and caregivers. The complete data are shown in Table 1.

\section{Factors and covariables associated with burden in the total sample across follow-up}

In the linear mixed analysis (fixed effects) the factors and covariables shown in Table 1 were introduced as time-variant independent variables, with the dependent variable being caregiver burden (ZBI). The patient variables associated with burden were behavioral and psychological symptoms (NPI: $F=18.9, p<0.001$ ), functional status (DAD: $F=14.8, p<0.001$ ), and cognitive status (MMSE: $F=2.4, p=0.047$ ). The caregiver factors associated with burden were SF-12 mental health $(F=43.9, p<0.001)$, SF-12 physical health $(F=8.5, p<0.001)$, the relationship to the patient $(F=8.1, p<0.001)$, the daily hours of care $(F=3.7$, $p=0.005)$, and being the sole caregiver $(F=3.2$, $p=0.012$ ). Gender, schooling, and age were not significant factors for either patients or caregivers.

\section{Growth mixture models of change in burden}

Linear and quadratic GMMs were fitted to the ZBI scores obtained at each assessment points, following the procedure described in the Methods section. In general, quadratic GMM showed the lowest BIC values, independently of the number of classes, thereby suggesting that a non-linear model fitted better the trajectories of ZBI scores over time. Table 2 shows the results of the GMM adjustment indices for 1 to 5 classes. The AIC and BIC values for a single class were, respectively, 7480.346 and 7512.377 . Increasing the number of classes to five reduced the AIC and BIC by 169.824 and 105.761 points, respectively. The LMR had $p$ values close to 0.05 when the model included two or three classes, although the entropy value was slightly worse for the two-class model. In addition, comparison of the model coefficients for the two-class and three-class models indicated that the latter was able to characterize the trajectory of three qualitatively different groups: (1) low and relatively stable severity of burden; (2) moderate and increasing severity; and (3) high and decreasing severity. 
Table 1

Socio-demographic and clinical data of patients and caregivers

\begin{tabular}{|c|c|c|c|c|c|c|}
\hline & \multirow{2}{*}{$\frac{\text { Baseline }}{1(n=330)}$} & \multirow{2}{*}{$\frac{12 \text { months }}{2(n=235)}$} & \multirow{2}{*}{$\begin{array}{l}24 \text { months } \\
3(n=166) \\
\end{array}$} & \multirow{2}{*}{$\begin{array}{l}36 \text { months } \\
4(n=118)\end{array}$} & \multicolumn{2}{|c|}{ Differences } \\
\hline & & & & & Test & $p$ \\
\hline \multicolumn{7}{|l|}{ Patient factors } \\
\hline Women, $n(\%)$ & $215(65.2)$ & $157(66.8)$ & $111(66.9)$ & $75(63.6)$ & 0.5 & $0.916^{1}$ \\
\hline School ( $\geq 8$ years), $n(\%)$ & $35(10.6)$ & $25(10.6)$ & $19(11.4)$ & $15(12.7)$ & 0.4 & $0.927^{1}$ \\
\hline Age, mean (SE) & $78.0(0.3)$ & $79.0(0.3)^{\mathrm{a}}$ & $80.0(0.3)^{\mathrm{b}, \mathrm{d}}$ & $81.0(0.3)^{\mathrm{c}, \mathrm{e}, \mathrm{f}}$ & 107.4 & $<0.001^{2}$ \\
\hline MMSE, mean (SE) & $17.9(0.2)$ & $17.6(0.2)$ & $17.4(0.3)$ & $14.8(0.4)^{\mathrm{c}, \mathrm{e}, \mathrm{f}}$ & 20.2 & $<0.001^{2}$ \\
\hline DAD, mean (SE) & $66.6(0.4)$ & $62.9(0.6)^{\mathrm{a}}$ & $60.0(0.7)^{\mathrm{b}, \mathrm{d}}$ & $56.7(0.8)^{\mathrm{c}, \mathrm{e}, \mathrm{f}}$ & 58.7 & $<0.001^{2}$ \\
\hline NPI, mean (SE) & $11.5(0.6)$ & $12.2(0.9)$ & $12.0(0.8)$ & $11.7(0.9)$ & 0.2 & $0.884^{2}$ \\
\hline \multicolumn{7}{|l|}{ Caregiver factors } \\
\hline Women, $n(\%)$ & $224(67.9)$ & $164(69.8)$ & $120(72.3)$ & $80(67.8)$ & 1.1 & $0.763^{1}$ \\
\hline School ( $\geq 8$ years), $n(\%)$ & $164(49.7)$ & $110(46.8)$ & $71(42.8)$ & $59(50.0)$ & 2.4 & $0.482^{1}$ \\
\hline \multicolumn{7}{|l|}{ Relationship, $n(\%)$} \\
\hline Spouse & $136(45.8)$ & $103(47.7)$ & $80(51.6)$ & $57(52.3)$ & 2.4 & $0.871^{1}$ \\
\hline Adult child (LP) & $65(21.9)$ & $46(21.3)$ & $31(20.0)$ & $19(17.4)$ & & \\
\hline Adult child (not LP) & $96(32.3)$ & $67(31.0)$ & $44(28.4)$ & $33(30.3)$ & & \\
\hline Sole caregiver, $n(\%)$ & $204(61.8)$ & $144(61.3)$ & $100(60.2)$ & $58(49.2)$ & 6.3 & $0.097^{1}$ \\
\hline Age, mean (SE) & $59.7(0.8)$ & $60.1(0.8)$ & $60.7(0.9)$ & $63.3(1.0)^{\mathrm{c}, \mathrm{e}, \mathrm{f}}$ & 5.7 & $\mathbf{0 . 0 0 1}^{2}$ \\
\hline Hours of care, mean (SE) & $2.3(0.0)$ & $3.6(0.1)^{\mathrm{a}}$ & $4.5(0.1)^{\mathrm{b}, \mathrm{d}}$ & $5.8(0.1)^{\mathrm{c}, \mathrm{e}, \mathrm{f}}$ & 270.9 & $<0.001^{2}$ \\
\hline $\mathrm{ZBI}$, mean (SE) & $41.1(0.7)$ & $42.6(0.7)^{\mathrm{a}}$ & $44.5(0.9)^{\mathrm{b}}$ & $44.7(1.1)^{\mathrm{c}}$ & 4.4 & $0.004^{2}$ \\
\hline SF-12, PH, mean (SE) & $49.9(0.5)$ & $49.5(0.6)$ & $49.1(0.7)$ & $49.0(0.8)$ & 0.4 & $0.697^{2}$ \\
\hline SF-12, MH, mean (SE) & $46.2(0.6)$ & $45.2(0.7)$ & $44.9(0.8)$ & $45.5(1.0)$ & 0.7 & $0.497^{2}$ \\
\hline
\end{tabular}

${ }^{1}$ Pearson $\chi^{2}$ test. $^{2} F$, ANOVA, linear mixed model, fixed effects; Means, estimated marginal; SE, standard error; Significant with Bonferroni post hoc contrasts: ${ }^{\mathrm{a}} 1-2,{ }^{\mathrm{b}} 1-3,{ }^{\mathrm{c}} 1-4,{ }^{\mathrm{d}} 2-3,{ }^{\mathrm{e}} 2-4,{ }^{\mathrm{f}} 3-4$. $p$-values $<0.05$ are shown in bold. MMSE, Mini Mental State Examination; DAD, Disability Assessment for Dementia; NPI, Neuropsychiatric Inventory; ZBI, Zarit Burden Interview; SF-12, Short Form of Health Survey; PH, physical health; MH, mental health. LP, living with patient; Hours of care, daily.

Table 2

Growth mixture models for caregiver burden (ZBI). Fit indices for one to five classes

\begin{tabular}{|c|c|c|c|c|c|}
\hline & One class & Two classes & Three classes & Four classes & Five classes \\
\hline Number of free parameters & 8 & 12 & 16 & 20 & 24 \\
\hline Akaike information criterion & 7480.346 & 7403.097 & 7365.038 & 7329.355 & 7310.522 \\
\hline Bayesian information criterion & 7512.377 & 7451.144 & 7429.100 & 7409.433 & 7406.616 \\
\hline Entropy & - & 0.735 & 0.892 & 0.795 & 0.152 \\
\hline \multirow[t]{2}{*}{ Lo-Mendell-Rubin test } & - & 2 vs. 1 & 3 vs. 2 & 4 vs. 3 & 5 vs. 4 \\
\hline & - & $p=0.0059$ & $p=0.0463$ & $p=0.4174$ & $p=0.1529$ \\
\hline \multirow[t]{5}{*}{$\mathrm{N}$} & 330 & $\mathrm{C}_{1}=277$ & $\mathrm{C}_{1}=244$ & $\mathrm{C}_{1}=233$ & $\mathrm{C}_{1}=211$ \\
\hline & & $\mathrm{C}_{2}=53$ & $\mathrm{C}_{2}=46$ & $\mathrm{C}_{2}=46$ & $\mathrm{C}_{2}=48$ \\
\hline & & & $\mathrm{C}_{3}=40$ & $\mathrm{C}_{3}=44$ & $\mathrm{C}_{3}=48$ \\
\hline & & & & $\mathrm{C}_{4}=8$ & $\mathrm{C}_{4}=19$ \\
\hline & & & & & $\mathrm{C}_{4}=4$ \\
\hline
\end{tabular}

ZBI, Zarit Burden Interview.

\section{Trajectories of caregiver burden}

The analysis of the mixture model applied to the variable caregiver burden identified three caregiver trajectories over the three-year period. The fixed effects of burden in the groups considered in the linear mixed model showed significant differences across the follow-up $(F=73.5, p<0.001)$.

With regard to the simple effects of the estimated marginal means, the largest group (G3, Reference: low burden) showed only a slight increase in burden $(F=3.1, p=0.024)$. Caregivers in G1 (burden decreases) presented high burden at the baseline assessment, which then decreased significantly over the three years $(F=21.1, p<0.001)$. Conversely, the initially moderate level of burden in G2 (burden increases) increased significantly over the follow-up period $(F=50.7, p<0.001)$. The level of burden in the trajectories of groups 1 and 2 was always above the overall mean. The value obtained in the comparison of group means was lower at 36 months than at baseline, suggesting a certain degree of convergence in trajectories by the final assessment point. Figure 1 displays the trajectories in caregiver burden over the 36 months of the study. 


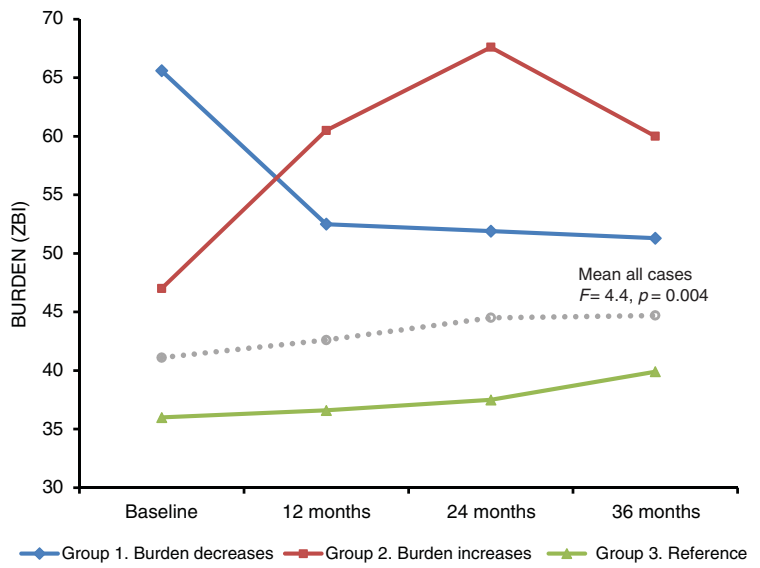

Fig. 1. Trajectories of caregiver burden (ZBI), Mixture model.

\section{Scores and frequencies for the factors associated} with trajectories of burden

The NPI score (behavioral and psychological symptoms) of patients in G1 (burden decreases) fell by 8.1 points over the 36 months $(F=2.3, p=0.069)$, whereas during the same period the NPI score of patients in $\mathrm{G} 2$ (burden increases) rose by 3.8 points $(F=2.6, p=0.052)$. The differences between groups remained significant across all four assessment points, most notably that between G2 (burden increases) and G3 (reference group). NPI scores were always higher in groups $\mathrm{G} 1$ and $\mathrm{G} 2$.

Over the 36 months of follow-up the functional status (DAD) of patients deteriorated significantly in all three groups: G1 $(F=6.5, p<0.001), \mathrm{G} 2(F=26.1$, $p<0.001)$, and G3 $(F=33.2, p<0.001)$. The differences between groups remained significant across all four assessment points, most notably that between $\mathrm{G} 2$ (burden increases) and G3 (reference group). DAD scores were always lower in groups G1 and G2.

The mental health (SF-12) of caregivers in G2 (burden increases) worsened significantly (6.9-point decrease) over time $(F=8.5, p<0.001)$. The differences between groups remained significant across the follow-up period, notably that between G2 (burden increases) and G3 (reference group). Mental health scores were always lower in G2. By contrast, caregivers in G1 showed an improvement in mental health (8-point increase) over the 36 months of follow-up $(F=1.9, p=0.124)$.

The relative proportions of caregivers belonging to each of the three family relationship groups (spouses, adult child living with patient, and adult child not living with patient) remained stable across the follow-up.
Group G1 (burden decreases) contained fewer spouses than adult children, whereas in G2 (burden increases) the number of spouses and of adult children living with the patient was greater than the number of adult children not living with the patient. In all three groups the relative proportions of caregivers by family relationship were significantly different at the first three assessment points: baseline $\left(\chi^{2}=28.7\right.$, $p<0.001), 12$ months $\left(\chi^{2}=20.7, p<0.001\right)$, and 24 months $\left(\chi^{2}=15.0, p=0.005\right)$.

With respect to being the sole caregiver, this was much more common in $\mathrm{G} 2$ (burden increases), where between $72 \%$ and $85 \%$ of caregivers did not share their role with anybody else. Furthermore, the proportion of sole caregivers in $\mathrm{G} 2$ remained significantly higher than in G1 and G3 throughout the follow-up period. The data for this analysis are shown in Supplementary Table 1.

\section{Multinomial multilevel regression analysis}

The aim of the multinomial multilevel regression was to identify the factors associated with the groups derived from the analysis of trajectories, with G3 (low burden) being taken as the reference group in each case.

Group 1 (burden decreases). A more deteriorated state in patients (high NPI scores and low DAD scores) increased the likelihood of belonging to this group. In caregivers, poorer mental health increased the likelihood of belonging to this group, whereas being a spouse caregiver reduced it.

Group 2 (burden increases). A more deteriorated state in patients (high NPI scores and low DAD scores) increased the likelihood of belonging to this group. In caregivers, poorer mental health and being the sole caregiver increased the likelihood of belonging to this group; spouses and adult children who lived with the patient were also more likely to belong to this group.

The factors that distinguish these two groups are being the sole caregiver and being an adult-child caregiver who lives with the patient, both of which increased the likelihood of belonging to Group 2. Data from the multinomial regression analysis are shown in Table 3.

\section{Burden with respect to family relationship and the nature of the caregiving role}

Scores for caregiver burden were also analyzed in relation to the factors that were shown to be significant in the multilevel multinomial regression: family relationship (spouse, adult child living with patient, and 
Table 3

Multinomial multilevel regression analysis of the trajectories of caregiver burden

\begin{tabular}{|c|c|c|c|c|c|c|}
\hline Method: Forward stepwise & $\mathrm{B}$ & $(\mathrm{SE})$ & Wald & $p$ & OR & $95 \% \mathrm{CI}$ \\
\hline \multicolumn{7}{|l|}{ Group 1 (Burden decreases) } \\
\hline \multicolumn{7}{|l|}{ Patient factors } \\
\hline Behavioral (NPI) & 0.03 & $(0.01)$ & 13.75 & $<0.001$ & 1.03 & $1.01-1.06$ \\
\hline Functional (DAD) & -0.04 & $(0.01)$ & 8.84 & 0.003 & 0.95 & $0.92-0.98$ \\
\hline \multicolumn{7}{|l|}{ Caregiver factors } \\
\hline Mental health (SF-12) & -0.04 & $(0.01)$ & 17.90 & $<0.001$ & 0.95 & $0.93-0.97$ \\
\hline \multicolumn{7}{|l|}{ Caregiving role } \\
\hline Sole caregiver (1) & 0.19 & $(0.29)$ & 0.44 & 0.506 & 1.21 & $0.68-2.17$ \\
\hline \multicolumn{7}{|l|}{ Shared (2): Reference } \\
\hline \multicolumn{7}{|l|}{ Family relationship } \\
\hline Spouse (1) & -1.15 & $(0.36)$ & 9.80 & 0.002 & 0.31 & $0.15-0.65$ \\
\hline Adult child $(\mathrm{LP}=2)$ & 0.28 & $(0.33)$ & 0.72 & 0.394 & 1.32 & $0.69-2.55$ \\
\hline \multicolumn{7}{|c|}{ Adult child (not LP=3): Ref. } \\
\hline \multicolumn{7}{|c|}{ Group 2 (Burden increases) } \\
\hline \multicolumn{7}{|l|}{ Patient factors } \\
\hline Behavioral (NPI) & 0.03 & $(0.01)$ & 11.88 & 0.001 & 1.03 & $1.01-1.05$ \\
\hline Functional (DAD) & -0.04 & $(0.01)$ & 10.58 & 0.001 & 0.96 & $0.93-0.98$ \\
\hline \multicolumn{7}{|l|}{ Caregiver factors } \\
\hline Mental health (SF-12) & -0.06 & $(0.01)$ & 39.80 & $<0.001$ & 0.93 & $0.92-0.95$ \\
\hline \multicolumn{7}{|l|}{ Caregiving role } \\
\hline Sole caregiver $(1)$ & 1.25 & $(0.29)$ & 18.72 & $<0.001$ & 3.51 & $1.98-6.21$ \\
\hline \multicolumn{7}{|l|}{ Shared (2): Reference } \\
\hline \multicolumn{7}{|l|}{ Family relationship } \\
\hline Spouse (1) & 0.96 & $(0.37)$ & 6.52 & 0.011 & 2.62 & $1.25-5.51$ \\
\hline Adult child $(\mathrm{LP}=2)$ & 1.83 & $(0.39)$ & 21.78 & $<\mathbf{0 . 0 0 1}$ & 6.24 & $2.89-13.47$ \\
\hline \multicolumn{7}{|c|}{ Adult child (not LP=3): Ref. } \\
\hline \multicolumn{7}{|c|}{ Model Fitting final } \\
\hline \multicolumn{7}{|c|}{ Fitting Criteria. -2 Log Likelihood $=889.770$} \\
\hline Likelihood Ratio Tests. $\chi^{2}$ & & & & & & \\
\hline
\end{tabular}

adult child not living with patient) and the nature of the caregiving role (sole caregiver or shared responsibility). Across the four assessment points the fixed effects were as follows: for family relationship, $F=5.0$, $p<0.001$; for the nature of the caregiving role, $F=4.3$, $p<0.001$; and for the interaction between the two variables, $F=3.5, p<0.001$.

The simple effects analysis of estimated marginal means showed that adult-child caregivers who did not live with the patient had the lowest burden scores across the 36 months of follow-up, with the highest scores corresponding to adult children who did live with the patient. The burden scores of spouses fell somewhere between the two. However, the scores of adult-child caregivers did not change significantly during the 36 months, whereas the burden reported by spouses increased significantly over the same period $(F=6.5, p<0.001)$. In terms of the nature of the caregiving role, sole caregivers scored higher, and their burden increased significantly over the 36 months $(F=7.7, p<0.001)$. Combining these two variables showed that the increased burden experienced by sole caregivers during the follow-up period corresponded to both spouses $(F=8.4, p<0.001)$ and adult children living with the patient $(F=5.8, p=0.011)$. A significant increase of this kind was not, however, observed in the case of adult-child caregivers who did not live with the patient $(F=0.0, p=0.998)$.

In terms of the proportion of sole caregivers there were important differences between the three groups. The role of sole caregiver was most likely to be fulfilled by spouses (68-84\%), followed by adult children who lived with the patient (42-66\%), and adult children who did not live with the patient $(27-41 \%)$.

The data for the analysis of family relationships and the nature of the caregiving role are shown in Supplementary Table 2 .

\section{DISCUSSION}

Analysis of the overall sample

The results for the sample as a whole confirm that levels of burden are influenced by BPSD [2-6] and 
functional impairment [6-9] in the patient. In terms of caregiver factors, burden had a notable effect on their mental health [7, 13-16], and to a lesser extent on their physical health [17], although scores on mental and physical health did not change significantly across the follow-up period in the sample as a whole. Being the sole caregiver and spending more daily hours caring for the patient were other factors associated with burden. Living with the patient $[25,26]$ was associated with greater burden among adult-child caregivers. No differences were observed with respect to gender, age, or years of schooling in either patients or caregivers.

The trajectory of burden for the sample as a whole showed a slight increase over the follow-up period [3, 28]. Adult children living with the patient had the highest burden scores throughout the study; by contrast, the lowest burden scores corresponded to adult children who did not live with the patient. Spouses had intermediate scores, and were the only group to show a significant increase in burden. It should be noted, however, that the differences between subgroups tended to decrease by 36 months, suggesting that caregivers may adapt to the situation over time [29].

\section{Trajectories of caregiver burden}

The most novel contribution of this study concerns the identification of trajectories of burden among groups of caregivers. The largest group, G3, presented a more stable trajectory than did the other two groups (G1 and G2). This trajectory was associated with less burden, lower NPI scores, and higher scores on mental health. By contrast, the other two groups, which together accounted for a third of the sample, had a more uneven trajectory and reported higher levels of burden. The group in which burden increased over the followup period $(\mathrm{G} 2)$ was characterized by higher NPI scores and lower scores on mental health, the latter decreasing progressively over the 36 months. Conversely, in the group in which burden decreased over follow-up (G1), NPI scores decreased and scores on mental health increased over the follow-up period.

These data highlight the importance of BPSD (NPI score) and caregiver mental health in relation to burden [50]. It has previously been found that caregivers with depression, poorer mental health, and greater burden report more behavioral and psychological symptoms in the patient when asked to complete the NPI [51]. This suggests that burden could be reduced through the adequate management of the patient's behavioral and psychological symptoms, and by addressing the caregiver's mental health needs.

\section{Family relationship and cohabitation}

The caregiver's relationship to the patient and whether or not they live together is an aspect that has not been widely studied. Analyzing these variables separately may produce confounding results because the majority of spouses live with the patient, whereas this is not usually the case among adult-child caregivers. By combining these two variables the present study was able to show more clearly that both spouses and adult-child caregivers who live with the patient experience greater burden than do adult-child caregivers who have their own home. This finding needs to be analyzed in greater depth in order to identify the factors associated with lower levels of burden among adult-child caregivers who do not live with the patient; it may be that a greater use of external resources plays a relevant role here.

Another aspect that has received limited attention in previous research is the nature of the caregiving role, in other words, is responsibility shared or is the person the sole caregiver. The present analysis showed that sole caregivers experienced higher levels of burden. However, this factor was only significant for caregivers who lived with the patient (both spouses and adult children). In adult children not living with the patient, levels of burden did not differ significantly according to whether or not they were the sole caregiver.

\section{CONCLUSIONS}

The most relevant results of this study are as follows:

- The patient factors associated with increased caregiver burden were neuropsychiatric symptoms and functional impairment.

- The caregiver factors associated with increased caregiver burden were poorer mental health, being the sole caregiver, and living with the patient. These factors were more important in the group showing an increase in burden.

- Adult children living with the patient were the group with the highest burden throughout the follow-up period, whereas adult children who did not live with the patient reported lower levels of burden. Spouses had intermediate scores, but were the only group to show a significant increase in burden over the three years.

\section{FUTURE LINES OF RESEARCH}

The results highlight the need for more specific analyses of caregivers. In this context, it would be 
necessary not only to consider the primary stressors (those that depend on the patient) but also to pay special attention to attributes of caregivers, which can have a decisive influence on the burden they experience. Indeed, rather than treating caregivers as a homogeneous group, research needs to examine differences between them in terms of their relationship to the patient, their gender and ethnicity, whether or not they live with the patient, their use of support services, and the coping strategies they use [52].

The aim here would be to identify the aspects that need to be most closely targeted if we are to develop successful strategies for reducing caregiver burden. These more detailed analyses should also lead to the design of interventions that, as noted by previous studies, are tailored to individual needs [53-55], call for the active participation of caregivers [56], and are linked to the context in which care is provided [57]. Some homebased personalized interventions have been shown to be effective at reducing burden among caregivers $[58,59]$.

Finally, the results of the present study highlight the need for further research into the impact that access to external resources can have in terms of reducing burden.

\section{LIMITATIONS}

This study does have a number of limitations. The first is a common problem in longitudinal studies, namely the number of cases lost to follow-up. The percentage of lost cases (64.2\%) was, however, lower than that reported in other studies conducted over three years $(75.3 \%$ [4], 72.5\%, [7]). As in these studies, the patients lost to follow-up tended to be older and more impaired, with mortality being a frequent reason for cases being lost. This may have affected the results regarding burden, since the patients lost to follow-up were more impaired at baseline and, therefore, their respective caregivers might have contributed higher levels of burden to the analysis had they remained part of the sample.

A second limitation concerns the mental health of caregivers. This aspect was assessed on the basis of the mental component summary of the SF-12, with no specific scale being used to assess depression, a variable known to be relevant to caregiver burden. A third limitation derives from not having explored in detail the support services used by caregivers. Our results suggest that this aspect and its potential to reduce burden is an issue that needs to be examined in greater depth. Finally, the analysis did not explore how burden may have been affected by pharmacological treatments, whether psychotropic medication to reduce behavioral and psychological symptoms or the use of cholinesterase inhibitors to treat the disease as a whole.

While acknowledging these limitations, the study gains in consistency and robustness as a result of the sample size, the three-year follow-up, and the use of both the linear mixed model and the analysis of growth mixture models to identify trajectories of burden.

\section{ACKNOWLEDGMENTS}

The research was conducted in the Memory and Dementia Assessment Unit of the Santa Caterina Hospital (Salt, Spain) and formed part of the SIDEA research project (Seguimiento Integral de la Enfermedad de Alzheimer/Comprehensive Follow-Up of Alzheimer's Disease, 2003-12).

Authors' disclosures available online (http://www.jalz.com/disclosures/view.php?id=2277).

\section{SUPPLEMENTARY MATERIAL}

Supplementary tables are available in the electronic version of this article: http://dx.doi.org/10.3233/JAD140360 .

\section{REFERENCES}

[1] Zarit SH, Todd PA, Zarit JM (1986) Subjective burden of husbands and wives as caregivers: A longitudinal study. Gerontologist 26, 260-266.

[2] Agüera-Ortiz L, Frank-García A, Gil P, Moreno A (2010) Clinical progression of moderate-to-severe Alzheimer's disease and caregiver burden: A 12-month multicenter prospective observational study. Int Psychogeriatr 22, 12651279 .

[3] Brodaty H, Woodward M, Boundy K, Ames D, Balshaw R (2013) Prevalence and predictors of burden in caregivers of people with dementia. Am J Geriatr Psychiatry. doi: 10.1016/j.jagp.2013.05.004

[4] Gaugler JE, Davey A, Pearlin LI, Zarit SH (2000) Modeling caregiver adaptation over time: The longitudinal impact of behavior problems. Psychol Aging 15, 437-450.

[5] Germain S, Adam S, Olivier C, Cash H, Ousset PJ, Andrieu S, Vellas B, Meulemans T, Reynish E, Salmon E (2009) Does cognitive impairment influence burden in caregivers of patients with Alzheimer's disease? J Alzheimers Dis 17, 105-114.

[6] Slachevsky A, Budinich M, Miranda-Castillo C, NúñezHuasaf J, Silva JR, Muñoz-Neira C, Gloger S, Jimenez O, Martorell B, Delgado C (2013) The CUIDEME Study: Determinants of burden in Chilean primary caregivers of patients with dementia. J Alzheimers Dis 35, 297-306. 
[7] Gaugler JE, Kane RL, Kane RA, Newcomer R (2005) The longitudinal effects of early behavior problems in the dementia caregiving career. Psychol Aging 20, 100-116.

[8] Berger G, Bernhardt T, Weimer E, Peters J, Kratzsch T, Frolich L (2005) Longitudinal study on the relationship between symptomatology of dementia and levels of subjective burden and depression among family caregivers in memory clinic patients. J Geriatr Psychiatry Neurol 18, 119-128.

[9] Garre-Olmo J, López-Pousa S, Vilalta-Franch J, TurónEstrada A, Hernández-Ferrándiz M, Lozano-Gallego M, Fajardo-Tibau C, Puig-Vidal O, Moriente-Muñoz V, CruzReina MM (2002) Carer's burden and depressive symptoms in patients with Alzheimer s disease. State after twelve months. Rev Neurol 34, 601-607.

[10] Brodaty H, Connors MH, Xu J, Woodward M, Ames D (2014) Predictors of institutionalization in dementia: A three year longitudinal study. J Alzheimers Dis 40, 221-226.

[11] Turró-Garriga O, Garre-Olmo J, Vilalta-Franch J, CondeSala JL, de Gracia-Blanco M, López-Pousa S (2013) Burden associated with the presence of anosognosia in Alzheimer's disease. Int J Geriatr Psychiatry 28, 291-297.

[12] Conde-Sala JL, Reñé-Ramírez R, Turró-Garriga O, GascónBayarri J, Juncadella-Puig M, Moreno-Cordón L, Viñas Diez V, Garre-Olmo J (2013) Clinical differences in patients with Alzheimer's disease according to the presence or absence of anosognosia: Implications for perceived quality of life. J Alzheimers Dis 33, 1105-1116.

[13] García-Alberca JM, Lara JP, Berthier ML (2011) Anxiety and depression in caregivers are associated with patient and caregiver characteristics in Alzheimer's disease. Int J Psychiatry Med 41, 57-69.

[14] Mohamed S, Rosenheck R, Lyketsos CG, Schneider LS (2010) Caregiver burden in Alzheimer disease: Crosssectional and longitudinal patient correlates. Am J Geriatr Psychiatry 18, 917-927.

[15] García-Alberca JM, Cruz B, Lara JP, Garrido V, Lara A, Gris E (2012) Anxiety and depression are associated with coping strategies in caregivers of Alzheimer's disease patients: Results from the MÁLAGA-AD study. Int Psychogeriatr 24, 1325-1334.

[16] Springate BA, Tremont G (2014) Dimensions of caregiver burden in dementia: Impact of demographic, mood, and care recipient variables. Am J Geriatr Psychiatry 22, 294-300.

[17] Smith GR, Williamson GM, Miller LS, Schulz R (2011) Depression and quality of informal care: A longitudinal investigation of caregiving stressors. Psychol Aging 26, 584-591.

[18] Conde-Sala JL, Turró-Garriga O, Garre-Olmo J, VilaltaFranch J, López-Pousa S (2014) Discrepancies regarding the quality of life of patients with Alzheimer's disease: A threeyear longitudinal study. J Alzheimers Dis 39, 511-525.

[19] Conde-Sala JL, Reñé-Ramírez R, Turró-Garriga O, GascónBayarri J, Campdelacreu-Fumadó J, Juncadella-Puig M, Rico-Pons I, Garre-Olmo J (2014) Severity of dementia, anosognosia and depression in relation to the quality of life of patients with Alzheimer's disease: Discrepancies between patients and caregivers. Am J Geriatr Psychiatry 22, 138-147.

[20] Rudd MG, Viney LL, Preston CA (1999) The grief experienced by spousal caregivers of dementia patients: The role of place of care of patient and gender of caregiver. Int J Aging Hum Dev 48, 217-240.

[21] Arai Y, Zarit SH, Sugiura M, Washio M (2002) Patterns of outcome of caregiving for the impaired elderly: A longitudinal study in rural Japan. Aging Ment Health 6, 39-46.
[22] Yeager CA, Hyer LA, Hobbs B, Coyne AC (2010) Alzheimer's disease and vascular dementia: The complex relationship between diagnosis and caregiver burden. Issues Ment Health Nurs 31, 376-384.

[23] Mahoney R, Regan C, Katona C, Livingston G (2005) Anxiety and depression in family caregivers of people with Alzheimer disease: The LASER-AD study. Am J Geriatr Psychiatry 13, 795-801.

[24] Sugihara Y, Sugisawa H, Nakatani Y, Hougham GW (2004) Longitudinal changes in well-being of Japanese caregivers: Variations across kin relationships. J Gerontol B Psychol Sci Soc Sci 59, P177-P184.

[25] Raccichini A, Castellani S, Civerchia P, Fioravanti P, Scarpino O (2009) The caregiver's burden of Alzheimer patients: Differences between live-in and non-live-in. Am J Alzheimers Dis Other Demen 24, 377-383.

[26] Kim H, Chang M, Rose K, Kim S (2012) Predictors of caregiver burden in caregivers of individuals with dementia. $J A d v$ Nurs 68, 846-855.

[27] Gaugler JE, Roth DL, Haley WE, Mittelman MS (2011) Modeling trajectories and transitions: Results from the New York University caregiver intervention. Nurs Res 60(Suppl), S28S37.

[28] Vitaliano PP, Russo J, Young HM, Teri L (1991) Predictors of burden in spouse caregivers of individuals with Alzheimer's disease. Psychol Aging 6, 392-402.

[29] Choi CW, Stone RA, Kim KH, Ren D, Schulz R, Given CW, Given BA, Sherwood PR (2012) Group-based trajectory modeling of caregiver psychological distress over time. Ann Behav Med 44, 73-84.

[30] Taylor DH Jr, Kuchibhatla M, Østbye T (2008) Trajectories of caregiving time provided by wives to their husbands with dementia. Alzheimer Dis Assoc Disord 22, 131-136.

[31] Molyneux GJ, McCarthy GM, McEniff S, Cryan M, Conroy RM (2008) Prevalence and predictors of carer burden and depression in carers of patients referred to an old age psychiatric service. Int Psychogeriatr 20, 1193-1202.

[32] Conde-Sala JL, Garre-Olmo J, Turró-Garriga O, VilaltaFranch J, López-Pousa S (2010) Differential features of burden between spouse and adult-child caregivers of patients with Alzheimer's disease: An exploratory comparative design. Int J Nurs Stud 47, 1262-1273.

[33] Kjällman-Alm A, Norbergh KG, Hellzen O (2013) What it means to be an adult child of a person with dementia. Int $J$ Qual Stud Health Well-being 8, 21676.

[34] Perrig-Chiello P, Hutchison S (2010) Family caregivers of elderly persons a differential perspective on stressors, resources, and well-being. GeroPsych 23, 195-206.

[35] Pinquart M, Sörensen S (2011) Spouses, adult children, and children-in-law as caregivers of older adults: A meta-analytic comparison. Psychol Aging 26, 1-14.

[36] Rinaldi P, Spazzafumo L, Mastriforti R, Mattioli P, Marvardi M, Polidori MC, Cherubini A, Abate G, Bartorelli L, Bonaiuto S, Capurso A, Cucinotta D, Gallucci M, Giordano M, Martorelli M, Masaraki G, Nieddu A, Pettenati C, Putzu P, Tammaro VA, Tomassini PF, Vergani C, Senin U, Mecocci P (2005) Predictors of high level of burden and distress in caregivers of demented patients: Results of an Italian multicenter study. Int $J$ Geriatr Psychiatry 20, 168-174.

[37] Serrano-Aguilar PG, López-Bastida J, Yanes-López V (2006) Impact on health-related quality of life and perceived burden of informal caregivers of individuals with Alzheimer's disease. Neuroepidemiology 27, 136-142. 
[38] Muthén B (2004) Latent variables analysis: Growth mixture modelling and related techniques for longitudinal data. In The Sage Handbook of Quantitative Methodology for the Social Sciences, Kaplan D, ed. Sage Publications, Newbury Park CA, pp. 345-368.

[39] American Psychiatric, Association (2001) Manual Diagnóstico y Estadístico de los Trastornos Mentales, 4th ed., texto revisado (DSM-IV-TR), Masson, Barcelona.

[40] McKhann G, Drachman D, Folstein M, Katzman R, Price D, Stadlan EM (1984) Clinical diagnosis of Alzheimer's disease: Report of the NINCDS-ADRDA Work Group under the auspices of Department of Health and Human Services task force on Alzheimer's disease. Neurology 34, 939-944.

[41] Roth M, Tym E, Mountjoy CQ, Huppert FA, Hendrie H, Verma S, Goddard R (1986) CAMDEX. A standardised instrument for the diagnosis of mental disorder in the elderly with special reference to the early detection of dementia. $\mathrm{Br}$ J Psychiatry 149, 698-709.

[42] Folstein MF, Folstein SE, McHugh PR (1975) "Mini Mental State". A practical method for grading the cognitive state of patients for the clinician. J Psychiatr Res 12, 189-198.

[43] Gélinas I, Gauthier L, McIntyre M, Gauthier S (1999) Development of a functional measure for persons with Alzheimer's disease: The Disability Assessment for Dementia. Am J Occup Ther 53, 471-481.

[44] Cummings JL, Mega M, Gray K, Rosemberg-Thompson S, Carusi DA, Gornbein J (1994) The neuropsychiatric inventory. Comprehensive assessment of psychopathology in dementia. Neurology 44, 2308-2314.

[45] Ware JE, Jr., Kosinski M, Keller SD (1996) A 12-Item ShortForm Health Survey: Construction of scales and preliminary tests of reliability and validity. Med Care 34, 220-233.

[46] Akaike H (1987) Factor analysis and AIC. Psychometrika 52, 317-332.

[47] Schwarz G (1978) Estimating the dimension of a model. Ann Statist 6, 461-464.

[48] Lo Y, Mendell N, Rubin D (2001) Testing the number of components in a normal mixture. Biometrika 88, 767-778.
[49] Hedeker D (2003) A mixed-effects multinomial logistic regression model. Stat Med 22, 1433-1446.

[50] Mioshi E, Bristow M, Cook R, Hodges JR (2009) Factors underlying caregiver stress in frontotemporal dementia and Alzheimer's disease. Dement Geriatr Cogn Disord 27, 76-81.

[51] Conde-Sala JL, Reñé-Ramírez R, Turró-Garriga O, GascónBayarri J, Juncadella-Puig M, Moreno-Cordón L, Viñas Diez V, Vilalta-Franch J, Garre-Olmo J (2013) Factors associated with the variability in caregiver assessments of the capacities of the patients with Alzheimer's disease. J Geriatr Psychiatry Neurol 26, 86-94.

[52] Gallagher-Thompson D, Coon DW (2007) Evidence-based psychological treatments for distress in family caregivers of older adults. Psychol Aging 22, 37-51.

[53] Etters L, Goodall D, Harrison BE (2008) Caregiver burden among dementia patient caregivers: A review of the literature. J Am Acad Nurse Pract 20, 423-428.

[54] Selwood A, Johnston K, Katona C, Lyketsos C, Livingston $\mathrm{G}$ (2007) Systematic review of the effect of psychological interventions on family caregivers of people with dementia. $J$ Affect Disord 101, 75-89.

[55] Brodaty H, Arasaratnam C (2012) Meta-analysis of nonpharmacological interventions for neuropsychiatric symptoms of dementia. Am J Psychiatry 169, 946-953.

[56] Pinquart M, Sörensen S (2006) Helping caregivers of persons with dementia: Which interventions work and how large are their effects? Int Psychogeriatr 18, 577-595.

[57] Beinart N, Weinman J, Wade D, Brady R (2012) Caregiver burden and psychoeducational interventions in Alzheimer's disease: A review. Dement Geriatr Cogn Dis Extra 2, 638-648.

[58] Teri L, Mc Curry S, Logsdon R, Gibbons LE (2005) Training community consultants to help family members improve dementia care: A randomized controlled trial. Gerontologist 45, 802-811.

[59] Gitlin L, Corcoran M, Winter L, Boyce A, Hauck WW (2001) A randomized, controlled trial of a home environmental intervention: Effect on efficacy and upset in caregivers and daily function of persons with dementia. Gerontologist 41, 4-14. 